\title{
Classical anomia: a neuropsychological perspective on speech production
}

\author{
Matthew A. Lambon Ralph ${ }^{\mathrm{a}, *}$, Karen Sage $^{\mathrm{b}}, \mathrm{Jo}_{\mathrm{O}}$ Roberts $^{\mathrm{c}}$ \\ ${ }^{a}$ MRC Cognition and Brain Sciences Unit, 15 Chaucer Road, Cambridge CB2 2EF, UK \\ ${ }^{\mathrm{b}}$ University of Manchester, $U K$ \\ ${ }^{\mathrm{c}}$ York District Hospital, York, UK
}

Received 13 November 1998; received in revised form 15 March 1999; accepted 30 March 1999

\begin{abstract}
We present data collected from two anomic aphasics. Thorough assessment of comprehension, oral reading and repetition revealed no underlying impairments suggesting that both patients were examples of classical anomia-word-finding difficulties without impaired semantics or phonology. We describe a series of experiments in which the degree of anomia was both increased and decreased, by cueing or priming with either a semantically related word or the target item. One of the patients also presented with an 'acquired' tip-of-the-tongue phenomenon. He was able to indicate with a high-degree of accuracy the syllable length of the target, and whether or not it was a compound word. Neither patient could provide the first sound/letter. The data are discussed in terms of discrete two-stage models of speech production, an interactive-activation theory and a distributed model in which the positive and negative computational consequences of the arbitrary relationship between sound and meaning are emphasised. (C) 1999 Elsevier Science Ltd. All rights reserved.
\end{abstract}

\section{Introduction}

All models of speech production assume that naming can falter for a number of reasons and that these different types of failure reflect the underlying organisation of speech production. Thus with careful study of patients with word-finding difficulties, it should be possible to improve our knowledge of the representations and processes that are required when moving from meaning to speech.

\subsection{Does classical anomia really exist?}

If we consider speech production from meaning to phonological encoding, then the first impairment that leads to anomia is damage to the semantic system itself. Disorders of conceptual memory typically result

\footnotetext{
* Corresponding author. Tel: 01223-335294; fax: 01223-359062.

E-mail address: matt.lambon-ralph@mrc-cbu.cam.ac.uk (M.A. Lambon Ralph).
}

in profound word-finding difficulties. In semantic dementia $[28,64]$, patients often present with a history of progressive anomia, although with further assessment comprehension deficits can be identified. The patients' gradual semantic deterioration is coupled to increasing word-finding difficulties. This semantic anomia can result in a pattern of semantic errors that seems to reflect the nature of the degrading semantic representations (cf. [27]). Of course, semantic anomia is not limited to progressive aphasia but can occur in other aetiologies too $[9,19,20,26,51]$.

It is possible, at least theoretically, to identify patients without semantic (nor phonological) impairment who present with word-finding difficulties: for which we adopt the term, classical anomia - first used by Geschwind [21] to describe patients who could not name an object but could easily pick the correct label from a range of possible names provided by the examiner. There are some patients for whom a post-semantic, pre-phonological impairment is reported to have been central to their anomia. Graham, Patterson and Hodges [24] reported longitudinal naming and compre- 
hension data collected from patient, FM. Although initially presenting with profound anomia and a mild comprehension impairment, over a two year period her word-finding deteriorated even further but her scores on various comprehension tests remained unchanged (see Fig. 2 in [24]). Gainotti, Silveri, Villa and Miceli [20] were able to divide a group of anomic patients into two sets, one with an accompanying semantic impairment in whom the degree of semantic impairment predicted the severity of anomia and another group who presented without a comprehension impairment. Interestingly, the range of naming accuracy for both groups was the same. This would seem to reject the possibility that the degree of anomia is only a function of the level of semantic impairment. Other patients have been reported with anomia who perform well on comprehension tests $[4,18,25,29,35,38,51,59]$ including the much cited case EST [33]. EST only managed to name $22 \%$ of the items from the Boston Naming Test [22] but performed within the normal range on a variety of taxing comprehension assessments including the Pyramids and Palm Trees Test [31] and the word-picture matching test constructed by Shallice and McGill [62] which includes very infrequent concrete, emotion and abstract targets.

These studies imply that speech production can break down as a result of a post-semantic, pre-phonological impairment. If we adopt the strictest criteria, however, most of these cases would not be called classical anomics. Let's consider first, the evidence presented against a semantic impairment. In this regard it is imperative to note that receptive comprehension assessments are nearly always less sensitive to a semantic impairment than expressive tasks. Thus for a patient to be described as being unlikely to have any central semantic impairment (of course it is impossible to prove the null hypothesis that the patient definitely has no deficit), assessment should include a wide range of sensitive comprehension tests that require precise understanding of infrequent concrete and abstract ${ }^{1}$ words which go beyond the items used in the production tasks - this is especially true if semantic representations exhibit graceful degradation [17] such that mild impairments lead to little or no measurable comprehension deficits. Some studies that have included a greater number of semantic tests have highlighted subtle semantic impairments. For example, two of the anomic patients described by Laine et al. [35] completed word-picture matching and classification tasks

\footnotetext{
${ }^{1}$ It may seem a little odd to include abstract word knowledge within the assessment of an anomic patient who cannot name pictures of concrete items. However, we believe it useful to include these items, as abstract concepts tend to be less familiar to normal subjects and thus potentially sensitive to any underlying semantic impairment.
}

without error-but when tested further the patients' performance was outside the normal range when they were required to pick a specific semantic feature for the unnamed pictures.

A small proportion of the patients noted above have been tested and have passed a wide variety of comprehension assessments (e.g. EST: [33]) but they do not meet the second part of the criteria for classical anomia because there is evidence for an impairment within phonology itself. Some patients produce phonologically related errors in naming $[4,33,51]$ or are unable to use phonology correctly when words and nonwords are presented for repetition and reading $[11,33,59]$. In summary, the existing literature provides little evidence for the existence of classical anomia. The word-finding difficulties described in most cases can be explained as a collateral effect of semantic and/ or phonological deficits.

\subsection{Manipulating the degree of anomia}

It has been known for some time that patients' word-finding difficulties can be alleviated, at least temporarily, if they are provided with an appropriate cue. Pease and Goodglass [55] presented a range of cues to an unselected group of aphasics with word-finding difficulties. Presenting the first sound of the target or a sentence to complete were the most effective types of cue. In addition they found that the effectiveness of cueing (overall) was related to the degree of anomiagreatest benefit was shown by the patients with the mildest impairment. Patterson, Purell and Morton [54] used a different method to improve performance. When the patients were unable to name a picture, the examiner provided the correct name to the patient, which they were asked to repeat. This repetition procedure was found to facilitate later retrieval if the picture was presented again after a few intervening trials. In a subsequent experiment Patterson et al. found a significant improvement in word retrieval if the patients were presented with the first phoneme and even more so when the length of the cue was progressively increased.

Attempts to improve patients' naming are relatively common. It is unusual to find reports of experiments in which the degree of anomia is temporarily increased. This is not surprising given that it seems a little cruel to increase a patient's deficit. However, the identification of a method, or methods, by which an impairment can be both increased and decreased may reveal a great deal about the underlying deficit and, in turn, about the nature of speech production itself. For the sake of brevity we shall postpone a comparison of three broad types of speech production theory (twostage lexical access, interactive activation models and distributed architectures) until all the relevant patient 
data has been described (see Discussion below). One of the most cited methods is the miscuing paradigm reported by Howard and Orchard-Lisle [30] for the globally aphasic patient, JCU. Her very poor naming could be improved when she was given the first phoneme of the correct name. When the experimenter provided an incorrect phonemic cue, JCU was most likely to produce the name of a semantically related item. Podraza and Darley [58] utilised a different method to augment patient's anomia. They found that patients' naming accuracy dropped if they heard a sequence of three semantically related names before attempting to name the target picture.

\subsection{Acquired tip-of-the-tongue phenomena}

A number of authors have noticed the parallel between anomic word-finding difficulties [33] and the tip-of-the-tongue (ToT) state that can occur for normal subjects $[6,46,47]$. There have been a few attempts to probe for ToT information when a patient is unable to name a target picture. One of the first was carried out by Goodglass and colleagues [23]. They found that a group of aphasic subjects often believed that they had an idea of what the word was, and were sometimes able to retrieve the correct length and first letter of the unnamed target. This ability varied across aphasic type being most common for conduction aphasics and least common for the anomic group. Gainotti et al. [20] found that four of the five anomics without semantic impairment were better than chance when required to guess the first letter of an unnamed target from a choice of four possible letters. In contrast, only two of the six patients with a semantic anomia performed above chance on this ToT task.

Some anomics can provide a surprising range of ToT information. For example, the French patient GM [25] was able to give the correct gender of an unnamed picture on $13 / 17$ occasions. He was able to provide the first letter on $60 \%$ of occasions along with some of the medial letters, however, he like some other patients seemed to have little or no knowledge of the target phonology [50]. Perhaps the most remarkable finding from this patient was his ability to give (at least on some occasions) the alternative meaning for the name of a picture that happened to be a homophone-an effect Henaff Gonon et al. labelled parasemia. So, for example, when unable to name a picture of a ruff (fraise in French) GM told the examiner that the target word was also the name of a fruit. GM's ability to provide the correct gender of an unnamed picture has been replicated in a study of an Italian anomic [3].

We present data below collected from two anomic patients. Our report is split into three main sections. First we demonstrate that both patients performed normally on a range of sensitive comprehension tests, never made phonological errors in naming and were able to read and repeat words and nonwords - thus meeting the strict criteria necessary to be described as classical anomics. In the second section we report the results of various techniques which attempted to improve or increase (albeit temporarily) the patients' degree of anomia while the final section focuses on their ability to retrieve ToT information.

\section{Case reports}

\subsection{Background}

Patient GM is a right-handed male electrician and mechanic who was born in 1955. In November 1994 he was involved in a road traffic accident which resulted in right orbital, left parietal and basal skull fractures. Initial CT scan revealed multiple deep-seated contusions and a small left parietal extra dural haematoma. Our investigation began 17 months later, at which time GM had fluent speech with occasional word-finding difficulties but no other aphasic deficits including (apparently) intact comprehension. He performed normally on a selection of tasks from the Birmingham Object Recognition Battery [60]. He scored $25 / 25$ on both the minimal feature and foreshortened matching assessments, and $63 / 64$ on the 'easy' object decision tests. GM's naming was initially assessed using the Boston Naming Test [22] on which he named $31 / 60$ correctly. When he was unable to name the pictures, GM's responses were particularly informative, so much so that they inspired some of the experimental investigations reported below. His most common error was to produce a circumlocution that included uniquely defining information (e.g., acorn $\rightarrow$ 'from a tree, an oak, like a seed'). Occasionally he produced the names of semantically related items that he always rejected as incorrect (suggesting intact comprehension) but found them frustrating as they seemed to 'block' the correct name. GM sometimes provided the correct number of syllables in an unnamed picture but could not get its first sound (e.g., pyramid $\rightarrow$ "the burial chamber for Egyptian kings... it's got three 'beats'; muzzle $\rightarrow$ 'it's for a dog to wear if they give you a problem, I'm thinking of mask, no, it's got two beats'; unicorn $\rightarrow$ 'it's a horse of types, non-existent,... two beats, no, that's zebra, three.'; escalator $\rightarrow$ 'stair case, automatic stair case... it's a thing I've actually installed... automatic... electric... sounds a bit like 'radiator'.") One of his most striking responses was to the picture of a seahorse: 'I used to have these in the fish tank... tortoise is going through my mind, it's a word made up of two other words, like toad-stool. It has a land animal's name in it'. As soon as he was 
Table 1

GM's and JS's performance across a variety of semantic tests

\begin{tabular}{|c|c|c|c|c|}
\hline Test & & GM & JS & Normal range \\
\hline PALPA $^{\text {a }}$ Written Word-Picture Matching & & $40 / 40$ & $39 / 40$ & $35-40$ \\
\hline PALPA $^{\text {a }}$ Spoken Word-Picture Matching & & $40 / 40$ & $39 / 40$ & $35-40$ \\
\hline BORB $^{\text {b }}$ Picture Association Match & & $30 / 30$ & $30 / 30$ & $21-30$ \\
\hline Pyramids and Palm Trees Test ${ }^{\mathrm{c}}$ (all picture version) & & $50 / 52$ & $51 / 52$ & $49-52$ \\
\hline \multirow[t]{3}{*}{ Shallice and McGill Spoken Word-Picture Matching ${ }^{\mathrm{d}}$} & Concrete & $28 / 30$ & $30 / 30$ & $27-30^{\mathrm{e}}$ \\
\hline & Emotion & $21 / 30$ & $27 / 30$ & $21-29^{\mathrm{e}}$ \\
\hline & Abstract & $11 / 15$ & $15 / 15$ & $11-15^{\mathrm{e}}$ \\
\hline \multirow[t]{2}{*}{ PALPA $^{\mathrm{a}}$ Written Word Association } & Concrete & $14 / 15$ & $15 / 15$ & $\mathrm{~m}=13.4(1.26)$ \\
\hline & Abstract & $8 / 15$ & $12 / 15$ & $\mathrm{~m}=12.3(1.82)$ \\
\hline \multirow[t]{2}{*}{ PALPA $^{\text {a }}$ Written Synonym Judgement } & High imageability & $29 / 30$ & $30 / 30$ & not available \\
\hline & Low imageability & $30 / 30$ & $29 / 30$ & not available \\
\hline
\end{tabular}

${ }^{a}$ PALPA: Psycholinguistic Assessments of Language Processing in Aphasia [34].

${ }^{\mathrm{b}}$ BORB: Birmingham Object Recognition Battery [60].

${ }^{\mathrm{c}}$ Pyramids and Palm Trees Test [21].

${ }^{\mathrm{d}}$ Shallice and McGill [62].

${ }^{\mathrm{e}}$ Norms collected from 10 undergraduates (aged 19-32).

provided with the correct initial phoneme, GM was invariably able to provide the correct name.

JS, a right-handed businessman, was also born in 1955. In May 1995, he suffered a head injury following a bicycle accident. This left him unconscious for two weeks and during this period he underwent neurosurgery to drain a haematoma. In June of the same year he was hit on the head during an assault. It is unclear whether this second incident resulted in any additional brain damage. A CT scan carried out one month later (July) revealed a large low density area in the left temporo-parietal region. A follow-up scan (performed in November) showed a wedge-shaped low density area in the left temporal lobe and a slight dilation of the temporal horn of the left lateral ventricle. Our investigation began 10 months post-onset. JS presented with fluent speech, occasional word-finding difficulties but no apparent comprehension impairment. His success or failure in naming specific items to confrontation was found to be highly consistent across testing sessions. The implications of these data are reported in a separate article [37].

JS performed without error on the same selection of BORB tasks as that given to GM. He was always more anomic than GM on the naming tests administered. For example, on the Boston Naming Test JS only managed to name $16 / 60$ correctly. His predominant errors were no responses although he was able to give precise circumlocutions when requested. Like GM, JS produced a number of semantic errors that were always rejected. In contrast to GM, JS did not seem to have any ToT information about unnamed pictures.

\subsection{Evidence for classical anomia}

Seven comprehension tasks were administered. The word-picture matching tasks from the PALPA battery [34] require the subject to match a spoken or written word to its corresponding picture. Each target is presented with a close-semantic, a distant-semantic, a visual and an unrelated distractor. For the BORB Association Match [60] and Pyramid and Palm Trees Test [31], a subject has to match a target picture to one of two alternative pictures on the basis of closest association (i.e. a palm tree and not a fir tree with the pyramid). The Shallice and McGill word-picture matching task [62] includes words of low frequency relating to concrete, abstract and emotional concepts (e.g., monocle, locket, forethought, supplication, impatience and guilt). Subjects are asked to pick which of four pictures best represents the meaning of the word presented by the examiner. The PALPA synonym judgement test contains pairs of abstract or concrete words that the patient has to sort into words of similar or unrelated meaning. Finally the PALPA concrete and abstract word association test requires the subject to pick another word from an array (the target word, a semantic foil, and two unrelated items which are semantically-related to each other) which is closest in meaning.

The patients' scores are shown in Table 1. Both GM and JS performed extremely well even on sensitive tasks like the Shallice and McGill word-picture matching test on which there was a spread in the scores collected from the undergraduate controls. Only GM's 
Table 2

GM's and JS's performance on tests of reading aloud and repetition

\begin{tabular}{|c|c|c|c|}
\hline Test & Word Type & GM & JS \\
\hline \multicolumn{4}{|l|}{ Reading Aloud } \\
\hline \multirow[t]{3}{*}{ Levels of regularity ${ }^{\mathrm{a}}$} & Regular & $39 / 40$ & $38 / 40$ \\
\hline & Mildly Irregular & $39 / 40$ & $40 / 40$ \\
\hline & Very Irregular & $38 / 40$ & $39 / 40$ \\
\hline \multirow[t]{2}{*}{ Strain et al. ${ }^{b}$} & List 1 & $94 / 96$ & $93 / 96$ \\
\hline & List 2 & $60 / 64$ & $61 / 64$ \\
\hline \multirow[t]{2}{*}{ Surface List ${ }^{\mathrm{c}}$} & Low Freq'-Regular & $40 / 42$ & $41 / 42$ \\
\hline & Low Freq'-Exception & $37 / 42$ & $37 / 42$ \\
\hline \multirow{3}{*}{$\begin{array}{l}\text { Syllable Length }{ }^{\mathrm{d}} \\
\text { (test no. } 30 \text { ) }\end{array}$} & 1 syllable & $7 / 8$ & $8 / 8$ \\
\hline & 2 syllables & $6 / 8$ & $8 / 8$ \\
\hline & 3 syllables & $8 / 8$ & $8 / 8$ \\
\hline \multirow{2}{*}{$\begin{array}{l}\text { Regularity }^{\mathrm{d}} \\
\text { (test no. 35) }\end{array}$} & Regular & $30 / 30$ & $30 / 30$ \\
\hline & Exception & $30 / 30$ & $29 / 30$ \\
\hline \multirow{2}{*}{$\begin{array}{l}\text { Object Names }^{\mathrm{d}} \\
\text { (test no. 53) }\end{array}$} & Regular & $20 / 20$ & $19 / 20$ \\
\hline & Exception & $18 / 20$ & $20 / 20$ \\
\hline \multirow{2}{*}{$\begin{array}{l}\text { Homophone }^{\mathrm{d}} \\
\text { (test no. 38) }\end{array}$} & Defining & $20 / 20$ & $20 / 20$ \\
\hline & Reading & $20 / 20$ & $20 / 20$ \\
\hline \multirow{4}{*}{$\begin{array}{l}\text { Nonword }^{\mathrm{d}} \\
\text { (test no. } 36 \text { ) }\end{array}$} & 3 letters & $6 / 6$ & $6 / 6$ \\
\hline & 4 letters & $5 / 6$ & $6 / 6$ \\
\hline & 5 letters & $4 / 6$ & $6 / 6$ \\
\hline & 6 letters & $4 / 6$ & $6 / 6$ \\
\hline \multicolumn{4}{|l|}{ Repetition } \\
\hline \multicolumn{2}{|l|}{$\begin{array}{l}\text { Word repetition } \\
\text { (test no. 9) }\end{array}$} & $80 / 80$ & $80 / 80$ \\
\hline \multirow[t]{3}{*}{ Nonword repetition $^{\mathrm{d}}$} & 1 syllable & $8 / 10$ & $10 / 10$ \\
\hline & 2 syllables & $8 / 10$ & $10 / 10$ \\
\hline & 3 syllables & $10 / 10$ & $10 / 10$ \\
\hline
\end{tabular}

a $[63]$.

b $[65]$.

${ }^{\mathrm{c}}[53]$.

d [34].

score for the abstract word association task could be considered to be outside the normal range.

Neither GM nor JS ever made a phonological error in naming to confrontation or (at least in the authors' presence) in spontaneous speech. In order to test their output phonology further a series of reading and repetition assessments were administered (see Table 2). Both patients made only occasional errors in reading and repetition (consistent with normal performance). The reading tests included the PALPA homophone definition and reading test (no. 38). As shown in Table 2, GM and JS were able to provide accurate definitions for all 20 homophones. This result adds further weight to the evidence in favour of preserved comprehension in these two patients.

The results from three tests of naming to confronta- tion are shown in Table 3 (further data from other naming tasks are reported in the two sections that follow). All the naming tests in this study (except the Boston Naming Test results shown in Table 3) were administered with a $5 \mathrm{~s}$ per item time limit as GM often felt that he was close to the name of the target pictures and without a deadline he would try for up to 1 or $2 \mathrm{~min}$ to retrieve the correct name (most often with no success). The scores for the Boston Naming Test are the same as those reported in the patient background (see above). Both patients were given the short naming test from the PALPA battery (test no. 53) and a selection of simple line drawings. Across all these tasks, GM's scores were consistently higher than those obtained by JS although both made a similar pattern of errors-predominantly no responses or short circumlocutions (given the time limit) and occasional (rejected) semantic errors.

\subsection{Manipulating the degree of anomia}

\subsubsection{Attempts to reduce anomia}

We completed six separate experiments designed to improve the patients' picture naming:

1. Identity priming: Pictures from the Boston Naming Test (BNT) were interleaved with written words. The patients were asked to (try to) name the pictures and to read the written words aloud. In the priming condition a target picture was presented after its name had been read (with two intervening trials-i.e., target name for reading, unrelated picture, unrelated word, target picture) and in the control condition the target was preceded by an unrelated word (this technique is very similar to that used previously by Breen and Warrington: [5]). Prime and control conditions were counterbalanced across two sessions (the test was split into odd and even items for each condition)

2. Longer-term identity priming: In order to test whether any priming effect could last for more than

Table 3

GM's and JS's naming performance

\begin{tabular}{|c|c|c|c|c|c|}
\hline \multirow[t]{3}{*}{ Test } & \multicolumn{3}{|l|}{ GM } & \multicolumn{2}{|l|}{ JS } \\
\hline & \multirow[b]{2}{*}{ Correct } & \multicolumn{2}{|c|}{ Errors $^{\mathrm{a}}$} & \multirow[b]{2}{*}{ Correct } & Errors $^{\mathrm{a}}$ \\
\hline & & $\mathrm{NR}$ & C S V P & & NR C S V P \\
\hline Boston Naming Test ${ }^{\mathrm{b}}$ & $31 / 60$ & 18 & 11300 & $16 / 60$ & $\begin{array}{lllll}38 & 3 & 3 & 0 & 0\end{array}$ \\
\hline Short Naming Test ${ }^{\mathrm{c}}$ & $32 / 40$ & 1 & 2500 & $26 / 40$ & $\begin{array}{lllll}11 & 0 & 3 & 0 & 0\end{array}$ \\
\hline 60 line drawings & $47 / 60$ & 9 & 2200 & $37 / 60$ & $\begin{array}{lllll}20 & 0 & 3 & 0 & 0\end{array}$ \\
\hline
\end{tabular}

${ }^{a}$ Key to error type: $\mathrm{NR}=$ no response, $\mathrm{C}=$ circumlocution, $\mathrm{S}=$ semantic, $\mathrm{V}=$ visual, $\mathrm{P}=$ phonological.

${ }^{\mathrm{b}}$ [22].

c [34]. 
Table 4

The effects of priming and cueing on GM's and JS's naming performance

\begin{tabular}{|c|c|c|c|c|c|c|c|c|c|c|c|c|c|}
\hline \multirow[t]{3}{*}{ Test } & & \multicolumn{6}{|l|}{ GM } & \multicolumn{6}{|l|}{ JS } \\
\hline & & \multirow[b]{2}{*}{ Correct } & \multicolumn{5}{|c|}{ Errors $^{\mathrm{a}}$} & \multirow[b]{2}{*}{ Correct } & \multicolumn{5}{|c|}{ Errors $^{\mathrm{a}}$} \\
\hline & & & NR & $\mathrm{C}$ & $\mathrm{S}$ & $\mathrm{V}$ & $\mathrm{P}$ & & NR & $\mathrm{C}$ & $\mathrm{S}$ & $\mathrm{V}$ & $\mathrm{P}$ \\
\hline \multirow[t]{2}{*}{ 1. Identity priming } & Control & $21 / 60$ & 29 & 4 & 4 & 0 & 0 & $9 / 60$ & 50 & 0 & 1 & 0 & 0 \\
\hline & Primed & $48 / 60$ & 7 & 0 & 5 & 0 & 0 & $34 / 60$ & 25 & 0 & 1 & 0 & 0 \\
\hline \multirow[t]{2}{*}{ 2. Long-term identity priming } & Control & $33 / 60$ & 19 & 5 & 3 & 0 & 0 & $22 / 60$ & 25 & 7 & 6 & 0 & 0 \\
\hline & Primed & $47 / 60$ & 10 & 1 & 2 & 0 & 0 & $24 / 60$ & 30 & 3 & 3 & 0 & 0 \\
\hline \multirow[t]{2}{*}{ 3. Initial phonemic cueing } & No cue & $115 / 140$ & 18 & 1 & 6 & 0 & 0 & $105 / 140$ & 21 & 6 & 8 & 0 & 0 \\
\hline & Cued & $134 / 140$ & 4 & 0 & 2 & 0 & 0 & $116 / 140$ & 14 & 2 & 8 & 0 & 0 \\
\hline \multirow[t]{3}{*}{ 4. Phonemic cueing of the GNT } & No cue & 6 & 19 & 3 & 2 & 0 & 0 & 4 & 24 & 2 & 0 & 0 & 0 \\
\hline & Cued & 14 & & & & & & 6 & & & & & \\
\hline & Total & $20 / 30$ & & & & & & $10 / 30$ & & & & & \\
\hline \multirow[t]{3}{*}{ 5. Phonemic cueing of disyllabic items } & No cue & $38 / 50$ & 7 & 2 & 3 & 0 & 0 & $29 / 50$ & 15 & 4 & 2 & 0 & 0 \\
\hline & 1st syllable & $46 / 50$ & 4 & 0 & 0 & 0 & 0 & $40 / 50$ & 8 & 0 & 2 & 0 & 0 \\
\hline & 2nd syllable & $44 / 50$ & 6 & 0 & 0 & 0 & 0 & $27 / 50$ & 19 & 2 & 2 & 0 & 0 \\
\hline \multirow[t]{2}{*}{ 6. Cueing syllable no. and stress pattern } & No cue & $64 / 87$ & 19 & 1 & 3 & 0 & 0 & $53 / 87$ & 6 & 9 & 9 & 0 & 0 \\
\hline & Cued & $75 / 87$ & 6 & 3 & 3 & 0 & 0 & $57 / 87$ & 7 & 5 & 8 & 0 & 0 \\
\hline
\end{tabular}

${ }^{a}$ Key to error type: $\mathrm{NR}=$ no response, $\mathrm{C}=$ circumlocution, $\mathrm{S}=$ semantic, $\mathrm{V}=$ visual, $\mathrm{P}=$ phonological.

two intervening trials (around $20 \mathrm{~s}$ ), a long-term priming experiment was conducted. In this version the BNT was administered on two separate occasions. Fifteen minutes prior to giving the test, the subjects were asked to read aloud the names of either the odd or the even items (the intervening period was taken up with other tests or general conversation).

3. Initial phonemic cueing: A set of 140 simple line drawings was used to test the effects of providing the initial phoneme of the correct name. This experiment also contained the semantic phoneme miscuing procedure (see section below). Thus the set was given on three occasions. Each time a third of the pictures was presented with either no cue, the first phoneme of the correct name, or the first phoneme of a semantically-related item [as per 30].

4. Phonemic cueing of the GNT: The Graded Naming Test [44] was administered in order to assess the efficacy of correct phonemic cueing on a set of relatively hard picture items. If the patient was unable to name the picture, he was asked to provide any ToT information (see Section below) and then he was cued with the first phoneme.

5. Phonemic cueing of disyllabic items: Fifty pictures with disyllabic names were presented with either no cue, the initial phoneme of the first syllable or the initial phoneme of the second (counterbalanced across three administrations). In order to minimise confusion, the design of the task and the exact nature of the cueing were explained to GM and JS. The correct position of the phonemic cue (i.e. first or second syllable) was indicated visually at the same time as the spoken cue was given (the examiner pointed to one of two horizontal lines depicting the first and second syllables).

6. Cueing syllable number and stress pattern: A selection of pictures with one, two and three syllable names (matched for word frequency) was presented with either no cue or with the correct syllable number and stress pattern. The cue was presented both visually (syllable number shown on a card as one, two or three horizontal lines) while the examiner produced the correct stress pattern superimposed on the appropriate number of schwas.

\subsection{Results}

The results from each of these experimental manipulations are shown in Table 4.

1. Identity priming: Both GM and JS benefited from reading the name of the target three trials before trying to name it (GM: McNemar $\chi^{2}=20.5$, $P<0.01 ; \quad$ JS: McNemar $\left.\chi^{2}=21.3, \quad P<0.01\right)$. Although there is a clear effect of primed over unprimed items in this paradigm, the unprimed 
scores for both patients seemed to be lower than when the test had been administered without any priming manipulation (that is, the first time the BNT had been given-see Table 3). If the first results are used as a new control baseline then both patients exhibited a facilitation of primed over control (GM: McNemar $\chi^{2}=11.1, \quad P<0.01 ; \quad$ JS: McNemar $\left.\chi^{2}=12.0, P<0.01\right)$ but also an inhibition of unprimed when compared with control which just failed to reach significance (GM: McNemar $\chi^{2}=3.68, \quad P=0.06 ; \quad$ JS: McNemar $\left.\chi^{2}=3.27, P=0.07\right){ }^{2}$

2. Long-term identity priming: When asked to read the names $15 \mathrm{~min}$ before being presented with the pictures, GM still showed a significant benefit (primed over unprimed: $\chi^{2}=10.6, P<0.01$; primed over control baseline: $\chi^{2}=10.2, P<0.01$ ) although there was no longer a measurable inhibition of the unprimed items. There were no significant differences between JS's primed naming when compared either with the unprimed or control baseline conditions.

3. Initial phonemic cueing: Providing the first phoneme of the target significantly improved GM's naming (McNemar $\chi^{2}=14.1, P<0.01$ ) and in fact there were only six of the 140 items that GM failed to name with the assistance of this cue. JS's score was improved by the first phoneme although the increase failed to reach significance (McNemar $\left.\chi^{2}=3.23, P<0.07\right)$. On this and other phonemic cueing assessments we observed an interesting phenomenon-occasionally the cue elicited the name of a semantically-related item that happened to share the initial phoneme (e.g., GM: harp +/hø/ $\rightarrow$ 'harmonica'; JS: clown $+/ \mathrm{k} \bullet / \rightarrow$ 'comic', pear $+/$ $\mathrm{p} \bullet / \rightarrow$ 'peach'). We shall comment on this finding below (see Discussion).

4. Phonemic cueing of the GNT: On this taxing naming task both patients performed relatively poorly (GM: 6/30; JS: 4/30). GM was able to produce some ToT information, for example, correctly specifying that two words were compounds (handcuffs and shuttlecock) although on these less frequent items his ability to produce information was reduced (see Section on ToT information below). When given the first phoneme GM produced the correct name for another 14 pictures, JS named six additional items. When added to their unassisted naming results, GM's combined score (20/30) approached the mean

\footnotetext{
${ }^{2}$ This effect has been reported recently for repetition priming experiments in normal subjects [16,66]. Although subjects respond more quickly to items they have experienced before, they also react more slowly to the unprimed items than do a set of control subjects who are seeing the whole stimulus set for the first time.
}

for the control group on this test (original norms; Mean $=22.5$, SD-4.3 [44]: new norms; Mean $=20.4$, $\mathrm{SD}=4.1$ [67]). JS's combined score $(10 / 30)$ was still some way off the normal range. For a number of items, the phonemic cue again elicited a semantically related word even for very low frequency items (e.g., GM: pagoda + /p•/ $\rightarrow$ 'pyramid'; JS: radius + / $\mathrm{r} \bullet / \rightarrow$ 'rhombus').

5. Phonemic cueing of disyllabic items: As before, GM and JS were helped by the provision of the initial phoneme of the first syllable (GM: McNemar $\chi^{2}=4.08, \quad P<0.05 ; \quad$ JS: McNemar $\quad \chi^{2}=4.34$, $P<0.05)$ but did not seem to be if the initial phoneme of the second syllable was given.

6. Cueing syllable number and stress pattern: Despite the complexities of this technique, GM's naming was improved when the examiner gave the number of syllables and target stress pattern (McNemar $\left.\chi^{2}=4.35, P<0.05\right)$. This is, perhaps, a little surprising given GM's already good knowledge of syllable length (see below). JS's naming accuracy was unchanged by this type of cue.

\subsubsection{Attempts to increase anomia}

Our attempts at temporary alleviation of anomia were relatively successful particularly for GM, though less so for JS (we shall comment on this further-see Discussion). We also discovered one way in which both patients' naming impairment could be augmented-naming of unprimed items was suppressed when they were presented along with recently primed pictures. We describe three experiments in which we attempted to increase GM's and JS's anomia.

1. Semantic priming: Both JS and GM produced occasional semantic errors (although these were subsequently rejected). As noted above GM complained that these semantically related items seemed to block his ability to produce the correct item. When target pictures were preceded by the written name, performance was improved. In this experiment we tested the reverse: if the patients read a semantically related word before a picture was presented would it increase their word-finding difficulties? This possibility was tested using the items from the BNT. Again written words were interleaved with the pictures such that targets were immediately preceded by a (close) semantically related word (e.g., ladder presented before stilts, calculator before abacus), or an unrelated item (the semantic primes reordered). Primed and unprimed items were counterbalanced across two sessions. The patients were instructed to read the words aloud and to try to name the pictures.

2. Semantic blocking: If producing a semantically re- 
Table 5

The effects of semantic priming, semantic blocking, miscueing, and phonological interlopers on GM's and JS's naming performance

\begin{tabular}{|c|c|c|c|c|c|c|c|c|c|c|c|c|c|}
\hline \multirow[t]{3}{*}{ Test } & & \multicolumn{6}{|l|}{ GM } & \multicolumn{6}{|l|}{ JS } \\
\hline & & \multirow[b]{2}{*}{ Correct } & \multicolumn{5}{|c|}{ Errors $^{\mathrm{a}}$} & \multirow[b]{2}{*}{ Correct } & \multicolumn{5}{|c|}{ Errors $^{\mathrm{a}}$} \\
\hline & & & NR & $\mathrm{C}$ & $\mathrm{S}$ & $\mathrm{V}$ & $\mathrm{P}$ & & NR & $\mathrm{C}$ & $\mathrm{S}$ & $\mathrm{V}$ & $\mathrm{P}$ \\
\hline \multirow[t]{2}{*}{ 1. Semantic priming } & Control & $38 / 60$ & 15 & 4 & 3 & 0 & 0 & $25 / 60$ & 21 & 7 & 7 & 0 & 0 \\
\hline & Primed & $24 / 60$ & 23 & 3 & 10 & 0 & 0 & $27 / 60$ & 15 & 7 & 11 & 0 & 0 \\
\hline \multirow[t]{2}{*}{ 2. Semantic blocking } & Random & $92 / 100$ & 0 & 6 & 2 & 0 & 0 & $49 / 100$ & 41 & 1 & 8 & 1 & 0 \\
\hline & Blocked & $76 / 100$ & 22 & 0 & 2 & 0 & 0 & $54 / 100$ & 43 & 1 & 2 & 0 & 0 \\
\hline \multirow[t]{2}{*}{ 3. Phonemic miscueing } & No cue & $115 / 140$ & 18 & 1 & 6 & 0 & 0 & $105 / 140$ & 21 & 6 & 8 & 0 & 0 \\
\hline & Cued & $106 / 140$ & 23 & 1 & 10 & 0 & 0 & $87 / 140$ & 23 & 8 & 22 & 0 & 0 \\
\hline
\end{tabular}

${ }^{a}$ Key to error type: $\mathrm{NR}=$ no response, $\mathrm{C}=$ circumlocution, $\mathrm{S}=$ semantic, $\mathrm{V}=$ visual, $\mathrm{P}=$ phonological.

lated item could suppress naming, it should be possible to demonstrate this effect without utilising cross-task priming. To test this, we asked GM and JS to name a set of 100 simple line drawings twice. On one occasion the items were presented in a random order but on the other, the items were blocked into 10 broad semantic categories (vehicles, tools and instruments, clothes, household items, environmental features, sea creatures and insects, body parts, domestic (UK) animals, foreign animals, vegetables and fruit).

3. Phonemic miscueing: We have already noted that the initial (correct) phoneme cueing experiment was conducted with a semantic distractor condition [as per 30]. Thus in one condition, the 140 pictures were presented with the first phoneme of a semantically related item, e.g., guitar $+/ \mathrm{v} /$ (for violin).

\subsection{Results}

The results from the three experiments are summarised in Table 5.

1. Semantic priming: Preceding a target picture with a semantically related word significantly reduced GM's naming score (McNemar $\chi^{2}=7.7, P<0.01$ ). Although there was a slight increase in the number of semantic errors in the primed condition (GM perseverated from the word to the picture on four occasions), the greatest change was in terms of no

\footnotetext{
${ }^{3}$ As we had given the BNT on several occasions, we administered the test again, one week later (without any experimental manipulation). The repeated use of this test seemed to have little long-term effect on their performance (GM: $31 / 60 \rightarrow 36 / 60$; JS: $16 / 60 \rightarrow 24 / 60$ ).

${ }^{4}$ Our split-half analysis does not combine to 100 because some of the categories had an odd number of items in them (the middle item from the categories in question was excluded from the analyses).
}

response errors. JS also perseverated from the written word on five occasions but the semantic primes did not significantly change his overall naming accuracy. ${ }^{3}$

2. Semantic blocking: GM's naming could be reduced by blocking the target pictures into broad semantic categories $\left(\mathrm{McNemar} \chi^{2}=8.04, P<0.01\right)$ but this technique seemed to have no effect on JS's performance. It is interesting to note that the semantic interference effect on GM's naming increased as he worked through the pictures within a semantic category. Thus if the items from the first half of a category are compared with the second half, GM's accuracy was found to decrease significantly as he proceeded through each category (41/47 vs 29/47: $\left.\chi^{2}=6.77, P<0.01\right){ }^{4}$

3. Phonemic miscueing: Presenting a picture with an incorrect phonemic cue suppressed performance in both patients although only the drop in JS's naming reached statistical significance (McNemar $\chi^{2}=10.3$, $P<0.01)$. This technique led to an increase in the semantic errors produced by JS although he subsequently rejected them all as being the correct name.

\subsection{Acquired tip-of-tongue phenomena}

Initial clinical assessment had revealed GM's remarkable ToT-like comments about pictures that he was unable to name (see Background). We conducted three further experiments to investigate the patients' ability to retrieve ToT information about unnamed items.

1. Compound names: Although unable to name the picture of a seahorse in the BNT, GM recalled that the target name was a compound word. In order to test this phenomenon further, we selected 58 pictures 
Table 6

GM's and JS's ability to retrieve tip-of-the-tongue information about unnamed pictures

\begin{tabular}{|c|c|c|c|c|c|c|c|c|c|c|c|c|c|}
\hline \multirow[t]{3}{*}{ Test } & & \multicolumn{6}{|l|}{ GM } & \multicolumn{6}{|l|}{ JS } \\
\hline & & \multirow[b]{2}{*}{ Correct } & \multicolumn{5}{|c|}{ Errors $^{\mathrm{a}}$} & \multirow[b]{2}{*}{ Correct } & \multicolumn{5}{|c|}{ Errors $^{\mathrm{a}}$} \\
\hline & & & NR & $\mathrm{C}$ & $\mathrm{S}$ & $\mathrm{V}$ & $\mathrm{P}$ & & NR & $\mathrm{C}$ & $\mathrm{S}$ & $\mathrm{V}$ & $\mathrm{P}$ \\
\hline \multicolumn{14}{|l|}{ 1. Compound names } \\
\hline \multirow[t]{3}{*}{ (a) Naming accuracy } & Overall & $91 / 116$ & 20 & 1 & 4 & 0 & 0 & $32 / 116$ & 67 & 4 & 13 & 0 & 0 \\
\hline & Compound & $41 / 58$ & & & & & & $17 / 58$ & & & & & \\
\hline & Non-comp' & $50 / 58$ & & & & & & $15 / 58$ & & & & & \\
\hline \multirow[t]{3}{*}{ (b) ToT identification } & Compound & $14 / 17$ & & & & & & $21 / 33$ & & & & & \\
\hline & Non-comp' & $7 / 8$ & & & & & & $20 / 33$ & & & & & \\
\hline & Overall & $21 / 25$ & & & & & & $41 / 66$ & & & & & \\
\hline \multicolumn{14}{|l|}{ 2. Syllable length } \\
\hline \multirow[t]{4}{*}{ (a) Naming accuracy } & Overall & $57 / 87$ & 24 & 0 & 5 & 1 & 0 & $38 / 87$ & 45 & 0 & 4 & 0 & 0 \\
\hline & 1 syllable & $20 / 29$ & & & & & & $13 / 29$ & & & & & \\
\hline & 2 syllables & $17 / 29$ & & & & & & $13 / 29$ & & & & & \\
\hline & 3 syllables & $20 / 29$ & & & & & & $12 / 29$ & & & & & \\
\hline (b) ToT identification & & $22 / 25$ & & & & & & $18 / 41$ & & & & & \\
\hline \multicolumn{14}{|c|}{ 3. Syllable length \& first letter/sound } \\
\hline (a) Naming accuracy & & $6 / 30$ & 19 & 3 & 2 & 0 & 0 & $4 / 30$ & 24 & 2 & 0 & 0 & 0 \\
\hline \multicolumn{14}{|l|}{ (b) ToT identification } \\
\hline \multirow[t]{2}{*}{ (i) Syllable length } & 1st half & $6 / 11(55 \%)$ & & & & & & $0 / 11$ & & & & & \\
\hline & 2nd half & $3 / 13(23 \%)$ & & & & & & $0 / 15$ & & & & & \\
\hline (ii) First letter & Overall & $1 / 24$ & & & & & & $1 / 26$ & & & & & \\
\hline
\end{tabular}

with compound names. Each compound was paired with a non-compound picture, matching pairwise for phoneme length and written and spoken frequencies (from the Celex database [2]). GM and JS were asked to name each picture. If they could not name an item, they were required to indicate (or, if uncertain, to guess) whether the target name was a compound word, or not.

2. Syllable length: GM had begun to indicate spontaneously how many syllables there were in the unnamed picture. We investigated this ability using a set of 87 pictures that had one, two, or three syllable names. Items were matched in triplicate for word frequency. Both patients were asked to name the pictures. If they could not name an item, they were required to indicate (or, if uncertain, to guess) whether the name of the picture was one, two or three syllables.

3. Syllable length and first letter/sound: Although able to retrieve some information about an unnamed picture GM rarely produced the first letter or sound (unlike other anomic patients, e.g., EST: [33]). When the examiner provided the first phoneme his naming was returned to near-normal levels (see above). In this experiment, if the patients were unable to name a picture, we asked them to provide the number of syllables and the first sound or letter (both free responses). We also wanted to investigate whether GM was able to retrieve the correct syllable length as pictures became progressively harder to name. Thus we used the items from the GNT in order to compare the first and second halves of the test for each type of sound knowledge. (This was actually administered along with the phonemic cueing experiment-see above.) The procedure was as follows: the patients attempted to name the pictures; if they could not, they were asked to indicate the length and first sound/letter. The examiner then provided the correct phonemic cue. (NB the syllable-length characteristics of the pictures contained in the GNT are as follows: 3 one-syllable, 18 twosyllable and 9 three-syllable names.)

\subsection{Results}

The results from the three ToT experiments are shown in Table 6 .

1. Compound names: GM was very accurate when asked to say whether an unnamed item was a compound word or not $(21 / 25,84 \%$ : Binomial, $\left.\mathrm{p}_{\text {chance }}=1 / 2, P<0.001\right)$. Although JS never offered ToT information spontaneously his ability to ident- 
ify the compound items was above chance $(41 / 66$, $62 \%$ : Binomial, $\mathrm{p}_{\text {chance }}=1 / 2, P=0.03$ ).

2. Syllable length: GM's ability to specify the length of an unnamed picture was confirmed in this forcedchoice paradigm $\left(22 / 25,88 \%\right.$ : Binomial, $\mathrm{p}_{\text {chance }}=1 /$ $3, P<0.001)$ but JS's score was not significantly better than chance $(18 / 41,44 \%$ : Binomial, $P=0.10)$.

3. Syllable length and first letter/sound: JS was unable to retrieve the length of the unnamed targets from the GNT, and he only guessed the correct first letter on $1 / 26$ occasions. We have already noted that GM spontaneously identified that two items from this test (handcuffs \& shuttlecock) were compound words. In addition he correctly indicated the length of the target on 9/24 occasions. This score was much lower than that found for the more familiar items contained in the previous experiment. If the test is split into two, we found that his ability decreased somewhat as the targets became less frequent $\left(1^{\text {st }}\right.$ half $\left.-6 / 11,55 \% ; 2^{\text {nd }}-3 / 13,23 \%\right)$. GM's knowledge of the first letter of an unnamed item was poor: he retrieved the correct letter on only one occasion, in addition to 6 incorrect guesses and 17 no responses. It seems very unlikely that GM had access to the first sound of unnamed targets, otherwise he could have facilitated his own naming back to very high levels of accuracy (as we have already seen, an initial phonemic cue restored his naming into the normal range: $20 / 30$ correct with a phonemic cue). In fact towards the end of our study, we discovered that GM had begun to recite covertly the letters of the alphabet in an attempt to cue himself on a systematic basis.

\section{Discussion}

We have presented data collected from two headinjured patients. Although both had clear word-finding difficulties in confrontational naming tasks, their comprehension seemed to be intact even when tested using sensitive assessments on which there was a range of normal (undergraduate) performance. Neither patient exhibited any signs of a disruption to phonologythey never made phonological real or nonword errors in naming and both had excellent reading and repetition. Thus both conform to the strict criteria for classical anomia, noted in the Introduction. If required the patients could give excellent circumlocutions about unnamed items. In time-limited experiments their predominant error type was a failure to respond. They also made a small number of semantic errors although neither patient accepted these as the correct names of the targets (another indication of excellent semantic knowledge). This suggests that semantic errors need not arise as a consequence of an impairment to the semantic system itself [11,49]. It is also important to note that JS's degree of anomia, in terms of overall accuracy, was consistently greater than GM's.

Anomia could be temporarily alleviated by shortterm (three trial lag) repetition priming or a cue containing the first phoneme of the target name (but not a phoneme contained later in the target). GM's performance was particularly sensitive to phonemic cueing. His naming accuracy could be restored to the normal range on the Graded Naming Test if he was provided with the first phoneme. His naming was also improved by very subtle sound cues such as the correct syllable number and stress pattern, or repetition priming over a longer delay (at least up to $15 \mathrm{~min}$ ). JS's impairment was less sensitive to limited positive cues, although with the use of a multi-phonemic or progressive cueing technique, even JS was able to name all pictures presented to him [37].

As well as ameliorating naming performance, we were able to demonstrate a number of ways in which the patients' anomia could be made worse. Naming was suppressed if the patients were given an incorrect phonemic cue. When asked to read a semantically related word immediately before a target was presented or if the pictures were blocked into broad semantic categories, GM's performance was significantly reduced. In addition we found limited evidence for an unexpected effect of repetition priming on unprimed items: the reduced naming of unprimed items approached significance suggesting that, as well as facilitating performance on the primed items, repetition priming also inhibited production of the unprimed set. This inhibition effect was not found after a 15 min delay, although priming still facilitated GM's naming.

GM, unlike JS, had a striking ability to produce tipof-the-tongue (ToT) information about unnamed items. In particular we were able to demonstrate tacit knowledge about target word-forms in terms of syllable length and whether they were compound or monomorphemic words. This ToT knowledge did not include the first sound or letter of the target word. It would seem that this absence of initial sound knowledge was critical to GM's impaired naming given the excellent results obtained with phonemic cueing (we shall return to this observation below). Although his ToT information was remarkably good, GM was not always able to indicate the correct length of an unnamed picture. In fact, his performance diminished in this regard, as the targets became less familiar and thus harder to produce.

Classical anomics like GM and JS provide us with a view of the impaired naming system which is appar- 
ently not due to damage either to semantic or phonological representations. Rather, their naming process seems to be 'caught' between the two. Consequently their data may give us useful insights into what processes/levels of representation need to be proposed between semantics and phonology. Before describing their data in terms of a distributed approach to speech production, we shall consider two alternative theories.

\subsection{Two-stage lexical access models.}

One of the most influential models of normal speech production is that proposed by Levelt $[39,40]$. In twostage lexical access models, speech production is split into a number of hierarchically arranged, discrete processing steps that enable the speaker to move efficiently from 'intention to speech'. We shall limit ourselves to considering the steps required to move from intention to a phonological form, (although this intermediate level of representation has to be encoded into phonetics units and eventually into motor articulation plans [39]). We begin at the point at which the speaker (either for picture naming or for spontaneous speech) formulates a 'message', or in more standard neuropsychological terms, retrieves the appropriate semantic or conceptual representation. Semantics then act as input to a two-stage lexical access process. In the first part, the lemma that corresponds to the conceptual representation is retrieved. This represents one single word in abstract form that is specified both semantically and syntactically. At this stage, no sound information is available. This lemma, in turn, activates its corresponding lexeme, which 'releases' or 'makes available' the metric structure and stress pattern along with the appropriate phonological units. Note that, although stored within one unit, metric structure and phonological segments are released separately and have to be recombined later (segment-to-frame association). Having arrived at this stage in the sequence, the speaker then has a phonologically encoded word ready for the additional processing required for eventual articulation.

This framework has typically been applied to results collected from speech production experiments in normal subjects $[32,41]$, the literature on normal speech errors [45], or the tip-of-the-tongue phenomenon in normal subjects [46]. The two stages contained in the model reflect a broad division that is observable from normal data: timed picture naming experiments point towards an early period of semantic activation, followed by a phonological stage that has little or no overlap with semantic activation [32]. In addition, normal speech errors can be divided into two main categories-semantic and phonological. Two-stage models are yet to have the same impact on neuropsy- chology although there are some notable exceptions [7,8,52].

How well do the data collected from GM and JS fit this two-stage model? At a brief glance, GM's profile might seem to provide a unique view upon the nature of post-lexeme, phonological encoding. When he was unable to name a target, he was often able to retrieve the syllable length though not the first phoneme. As we have noted, Levelt proposes that, following activation of the correct lexeme, metric structure and stress pattern are released separately from the constituent phonemes. This allows for the possibility that aphasic patients could present with a dissociation between these two types of information. Thus GM would be considered to have retrieved the correct lexeme and to have access to the metric structure but not the phonological segments. Without both types of information speech cannot proceed and GM is stuck in an 'acquired' ToT state. When he is given the first phoneme, however, segmental spell-out is started and GM's naming is returned to its premorbid level. JS's deficit, on the other hand, would reflect access up to activation of the lexeme (assuming the excellent comprehension implies intact lemmas: [52]) but he is unable to retrieve either metric structure or constituent phonemes.

If we consider all the data more closely, the fit provided by the two-stage models is not so good. It is argued that one of the main benefits of an abstract, localist word representation (the lemma) is that it overcomes the inherent difficulties of translating from a semantic representation that is arbitrarily aligned with its corresponding phonological form (see Section 3 below). This hurdle is overcome by the discrete two stage process: (a) from the many thousands of words in a person's vocabulary a single lemma is activated that matches the speaker's intended meaning; (b) having overcome the problem of translating the meaning into the verbal domain, the lemma can activate its corresponding lexeme that contains the correct phonological form. We have been able to demonstrate, however, that GM's and JS's anomia seems to have primarily arisen from an inability to resolve a single lexical item amongst various semantically related competitors (on some occasions a semantically-related word won outi.e. they made a number of overt semantic paraphasias and the key to manipulating their degree of anomia was the presence of a target/semantic cue or prime). This would place their deficit at access to the lemma level. Despite this unresolved semantic competition, GM was already gaining partial access to sound-based information - a post-lexeme impairment. At the very least this implies that the naming system is not characterised by discrete stages, but that sound encoding can begin before lemma selection has finished (see Section 2 below). Butterworth's two-stage model [7,8] allows 
for some ToT information to arise once a single word in the semantic lexicon has been selected. This might provide a step towards an explanation for GM's data. However, it would rely on a number of additional assumptions: (i) that the vector, or 'pointer' into the phonological lexicon, provided by the semantic lexicon can be a source of information about the target word's length and first sound, (ii) that the correct address into the phonological space is available before the lexicalsemantic competition is finished, (iii) that the vector does not always provide both the first phoneme and the syllable length.

The very discrete nature of these models does not lead to a natural explanation for two other findings. First, GM's ability to retrieve the correct number of syllables for a target was not perfect and was graded by the familiarity of the word. This suggests that a segmental spell-out deficit was not the only impairment, but that GM also had an additional (frequency sensitive) impairment to metrical spell-out too. Secondly, GM's naming could be improved with a 'metric' cue (number of syllables and stress pattern). This is surprising given that he so often knew the correct syllable length and that his primary deficit appeared to be one of segmental spell-out that requires phonemic cueing.

The patient data not only point towards a cascading system but also may require interactivity between levels. Initial phonemic cueing improved GM's naming to normal levels, while for JS a multi-phonemic or progressive cueing technique was required [37]. Thus sound-based information (particularly in a phonological form, but also in terms of syllables and stress pattern for GM) was the critical type of cue required to alleviate the semantically based competition that appeared to be at the root of the patients' anomia. This suggests that partial sound-based information can propagate back up through the system to reinforce the activation of the target lemma. As soon as a single lemma is selected, speech production can proceed in the normal way. (NB the assumption being made here is that phonemic cues cannot directly influence activation at the lemma level because these representations do not mark any sound-based information, but could be indirectly affected by feedback activation from the lexeme level.)

\subsection{Interactive models of speech production}

We have argued that our data support an interactive cascading approach to speech production. This is certainly not a new argument but has been suggested in other studies of aphasic and normal speech production $[36,42]$ which are informed by the interactive activation model of speech production proposed by Dell and colleagues $[13,15,16]$. The architecture of this implemented model is as follows: a concept is represented in terms of a collection of semantic features; when these features are turned on (either by a picture or an intended 'message') activation spreads down the model to a lexical layer. This causes a gradual rise in activation for a number of semantically related words, although the target item will typically be the most prominent as it corresponds most closely to the pattern of semantic features. Partially activated lexical units send activation back to the semantic feature level (the model is interactive) and down to a phoneme layer (activation cascades). Excitation reverberates in the model until, after a set number of processing steps, the most activated lexical entry is selected. As Dell et al. [16] note this lexical selection process is equivalent to the first step of the two-stage models described above (in fact they call this part lemma access) although, of course, in this version the model has cascading and interactive activation. Once a unique lexical unit is selected, a jolt of activation is applied to this word. Excitation passes up to and back from the word's associated semantic features and down to and up from the phonological layer. This second process (phonological access) continues until a certain number of processing cycles have occurred, at which time, the most highly activated phoneme units are selected.

Dell's model provides a two-step dynamic for lexical access and contains the cascading and interactive features. Thus, the model is able to account for the early semantic and late phonological activation found in normal studies [41], the broad division of speech errors into meaning-related and sound-based errors, and aspects of ToT phenomena in normal subjects. It overcomes the problem of the arbitrary relationship between semantics and phonology, and provides a set of units, like lemmas, for syntactical aspects of speech production (for an excellent summary, see [16] pp. 804-805). Dell et al. [16] used this architecture in an impressive attempt to fit the individual naming data of 23 aphasic patients. The model was first set up to match naming data collected from two groups of control subjects. Then the model's performance was varied via adjustment of two global parameters, $p$, the connection strength and, $q$, the decay rate (the globality assumption). By using these two factors, Dell et al. were able to simulate very closely the performance of 21 of the 23 aphasic patients.

It seems unlikely that by using these global parameters, a close fit to the results from JS and GM could be obtained in this model. Firstly, the two aphasic patients (VP and GB) in Dell et al. [16] for whom there was a poor match between simulation and observed data were individuals who made a large number of no response errors and/or descriptions (although the proportions for VP and GB were in fact much lower than that observed in the performances of JS and GM). Secondly, when the patient data were 
plotted against overall correct performance (Fig. 4, [16]) then the number of nonword, formal and unrelated errors was found to be an inverse function of accuracy. GM and JS never produced these errors.

It would seem that our data require an alternative approach. To be interpreted within this framework, we propose that the naming performance of GM and JS must reflect a reduced ability of the damaged model to resolve the semantically-based competition arising at the lexical layer during the first step of lexical access. There are a number of potential causes for this phenomenon: (i) the activation passing between the semantic and lexical layers is attenuated; (ii) the system sometimes fails to apply the second 'jolt' of activation to the target word; or (iii) if lateral inhibition were included at the lexical layer, the patient data could indicate reduced inhibition amongst lexical competitors. Although the implemented version of their model does not contain inhibitory connections, Dell et al. [16, p. 806] have noted the functional similarity between an additional 'jolt' of activation and lateral inhibition, as both act to enhance the most highly-activated unit over its other competitors (cf. [43]). We will propose an explanation in terms of a lack of inhibition. Although the target will be the most highly activated word, it will not be differentiated sufficiently from the other competitors for naming to proceed. A semantically related item may occasionally win out, especially when the target is much less familiar than the competitor. Due to the cascading nature of the model, partial sound-based information may become available when the target activation is greater than its competitors (but insufficient for full phonological access). Naming accuracy can be changed by manipulating the relative activation of target and competitor words. If a semantically related item is primed, naming performance will go down; if the target is enhanced, accuracy will increase $^{5}$. Additional activation at the phonological layer (phonemic cueing) will also affect lexical access because the model has feedback connections from the phoneme units to the word level. Thus, the correct phoneme will boost the activation of the target word while miscueing will enhance a lexical competitor. When competing items have similar levels of lexical ac-

\footnotetext{
${ }^{5}$ The suppression of unprimed items that we observed in JS and GM could result as follows. Lateral inhibition is generally implemented as a function of the activation of the sending units. As primed items become more activated, unprimed words will be inhibited further. Presumably this inhibition effect is relatively short-lived (as it requires the activation of lexical competitors) but the priming effect may have a more long-term (weight-changing) component that effectively makes the primed items more 'frequent' and thus lexically easier to activate.

${ }^{6}$ We note that Dell and his colleagues [16] suggest that lemma representations may serve a similar function to a set of hidden units between semantics and phonology.
}

tivation a longer phonemic cue may be necessary to elicit the target word [37,38].

\subsection{A distributed model of speech production}

To conclude our article, we wish to sketch out a possible distributed approach to speech production which does not contain any layers of localist units relating to specific individual words ${ }^{6}$. As far as we are aware, there are no published distributed models that directly address adult or aphasic speech production, but there is a closely related model of deep dyslexic reading [57] which translates orthography into phonology via semantic representations (there is no direct route from graphemes to phonemes). That is, Plaut and Shallice's model successfully computes phonology from meaning without a set of intervening localist units. In addition, Plaut and Kello [56] have described a model in which phonological representations arise from the interaction of speech production and comprehension. Thus one half of their network is trained to produce the correct phonetic representation from a semantic input. Currently, the model has been used to address developmental phenomena without application to adult or aphasic speech data.

If we are to adopt this approach, however, there are a number of basic phenomena that require explanation:

1. the mapping between meaning and sound is arbitrary

2. lexical access is rapid

3. the adult vocabulary is very large

4. speech production seems to involve an early stage of semantic activation followed by late phonological activation

5. there are two broad categories of aphasic errors and normal 'slips-of-the-tongue'

6. both normal and aphasic speakers sometimes have partial phonological knowledge about ToT words

7. there must be a locus for the impact of syntactical knowledge in speech production (this locus is the lemma level in Levelt's model)

A reason for positing at least one intermediate layer of localist word representations between semantics and phonology is that the mapping from meaning to sounds is an arbitrary one. Typically words of similar meaning have very different phonological forms (e.g., cat, dog), while those with similar sounds have disparate meanings (e.g., cat, mat). Most theorists [16] seem to view this arbitrary mapping as an unfortunate computational problem of natural language. If arbitrariness is a bad thing, however, why have natural languages evolved in this fashion rather than to produce a closer alignment between sound and meaning? We would like to propose the radical notion that this 
way of implementing the relationship between meaning and phonology may have useful functional/computational consequences.

Butterworth [8] and Levelt [40] both note that adults have a very large expressive vocabulary from which single items have to be retrieved exceedingly rapidly to produce the high speech rate observed in spontaneous conversation. A lexical layer containing a single unit for each word that is accessed in parallel would seem to provide a solution to all of points (1)-(3) above. However, rapid lexical access might also result from an arbitrary relationship encoded on direct but interactive connections between semantics and phonology. Consider the following example: if the intended target word is cat, semantic activation will gradually build up to form a representation of the meaning. This semantic representation will begin to activate the target phonology of cat and, to a lesser degree, the phonological representations of other semantically-related items (dog, fox, lion, tiger, etc). That is to say a semantic cohort (to borrow a term from [41]) will be partially activated within the phonological component of the system, and will interact with the semantic activation. As the relationship between meaning and sound is arbitrary, competitors of the target word will typically have no phonological overlap with the target. Thus, as soon as the activation of $/ \mathrm{krt} /$, due to its better fit to the semantic specification, even begins to lead the field, the cohort of potential words will be reduced rapidly to a very small number, most often to only one item. In our example, when the semantic representation of 'a furry four-legged creature with claws' combines with / $\mathrm{k} /$, there is only one item left. Compare this to the real problems that would be inherited if the system were set up so that meaning correlated more closely to sound (i.e., if $d o g$, fox, lion, tiger, etc. were more like cat, cap and $c a b)$. Having activated a semantic representation, it would be difficult to settle rapidly on the correct phonology of the desired target and thus to avoid a semantic error. This problem would also be found in reverse, that is, for comprehension. Poor articulation, impaired hearing or background noise would lead to a large number of phonological (and, if related, hence semantic) comprehension errors. So rather than treating the arbitrary relationship as an unfortunate mistake of human language, it is possible that we should view it as the key to another computational problem, that of rapid 'lexical access'.

What else leads from this arbitrary relationship? In order to commence activation of phonology, the semantic input would have to be very 'well-formed'

\footnotetext{
${ }^{7}$ We are indebted to David Plaut for advice on the time-course of semantic and phonological activation in the distributed model of deep dyslexic reading.
}

both in terms of quality and quantity of input. This means that the time course in 'lexical access' will be primarily semantic to begin with (while the meaning is formed). Although this gradual build up in semantic activation cascades to phonology, it will have little impact until the activation is strong and precise ${ }^{7}$. It is only at this point that the rapid cohort reduction and phonological 'encoding' will begin in earnest - that is, significant phonological activation will tend to occur only when semantic activation begins to reach asymptote (NB this seems functionally to be rather like a threshold of semantic activation which needs to be exceeded before a phonological representation is released: cf. the logogen model [48]). This, of course, provides an alternative mechanism for the apparent 'two-step' activation dynamic noted in point (4) above.

In the same way, it seems likely that speech errors, point (5), will also seem to reflect a two-step timecourse (just as they are proposed to do in the twostage or interactive models described above), even though the process is in fact cascaded and gradual. Some will occur in the 'semantic' phase (errors of meaning) while others will arise in the 'phonological' stage (errors of sound). Tip-of-the-tongue phenomena, point (6), could reflect the information that is available when semantic input to phonology is insufficient for the rapid cohort reduction to occur (or to be completed). At this point a 'clear' semantic representation may be formed (thus subjects 'know' the intended word) but the sound information will only be partial and might include the approximate word-shape and/or the first sound.

This leaves us with point (7) - if there are no intermediate word units (lemmas) between semantics and phonology, how are syntactical aspects of individual words encoded? This issue has been considered in light of other neuropsychological data by Caramazza [10]. In his 'Independent Network' (IN) model, Caramazza proposes a separate lexical-syntactical network, which is linked to lexical-semantic, lexical-phonological and lexical-orthographic systems. Each syntactical property will have a different pattern of connections with the semantic and phonological systems depending on whether meaning and/or sound predicts grammatical form [10, pp. 194-195]. In languages such as Italian and French in which names of inanimate objects have gender, for example, gender is unrelated to meaning but is highly (though not perfectly) predictable from phonology. This is reflected in the IN model as connections running from lexemes ('P-lexemes' in Caramazza's terminology) to the gender nodes, but no link from gender to semantics. A similar approach can be taken from a PDP perspective. Grammatical and morphological aspects of language can be encoded within networks that learn about the internal regularities of phonology and semantics/context (for some 
recent reviews for this approach see $[1,12,61]$. Other structural aspects of speech that are normally encoded in terms of specific units can be simulated in models that learn about the regularities within phonology itself [14].

In this distributed scheme, the performance of GM and JS reflects the computational requirements and consequences of the arbitrary mapping between meaning and sound. This relationship provides a natural mechanism for rapid 'lexical access' amongst thousands of words; but for cohort reduction to occur there must be strong and precise semantic activation. Without this degree of input, the speaker is left with 'word-finding' difficulties. In fact this hypothesis also provides a potential answer to why anomia is such a common phenomenon in aphasia, and why we all suffer from word-finding difficulties on a regular basis. If, as we assume is true for JS and GM, the semantic input is disrupted or attenuated ${ }^{8}$ there will be insufficient activation for word production to proceed. Progressive, or multi-phonemic cueing, can provide a window on this process. Two recent articles [37,38] report the results of progressive phonemic cueing in two anomic patients (JS again and MOS). Both patients had excellent comprehension and an absence of phonological disruption but apparently attenuated activation of phonology by meaning. Unlike GM, JS and MOS often required a cue containing more than one phoneme to elicit the target word. The errors that they produced in response to cues less than the length required for successful naming are instructive. For example, when presented with a picture of a beaver, MOS initially gave no response, after the cue $/ \mathrm{b} \bullet /$ She said 'badger'; and finally with /bi:/ she produced 'beaver'. For the picture of a hammock she initially named it as a 'swing'; after /h॰/ she produced 'harness' but in response to /hæ/she said 'hammock'. These results would seem to suggest that the patients had insufficient activation of the phonological level to begin cohort reduction. This process was started with an initial phonemic cue (reducing the cohort to a set including

\footnotetext{
${ }^{8}$ This might result from two different forms of damage. First, activation could be attenuated or disrupted by reducing the weights on the connections between semantics and phonology, or by removing a proportion of these links. The second alternative relies on a property of distributed models known as graceful degradation. Under the right circumstances, distributed models can be resistant to the effect of small amounts of damage (see Figs. 5 and 6 in [17]). A limited lesion to the units supporting semantic representations may not have a measurable effect on comprehension. Because these same units are used to initiate speech production, however, the effect of a reduced number of semantic units might be observed first in naming to confrontation. With greater degrees of damage both comprehension and naming would be effected. Thus mild damage to the semantic units would lead to anomia without comprehension impairment-i.e. the pattern seen in classical anomia.
}

semantically-related words that shared the same initial phoneme) but was completed when the combination of the multi-phonemic cue and any available activation of phonology by semantic knowledge was sufficient to reduce the cohort to the target alone. We assume that our attempts to manipulate the degree of anomia shown by JS and GM worked along the same lines. A cue or prime containing the correct phonology would assist in cohort reduction but incorrect phonological and/or semantic activation would hinder it.

Other results follow from the graded nature of computational models. If a difference in naming accuracy in some way reflects the underlying degree of activation of phonology by semantics, JS's lack of tip-ofthe-tongue information is linked directly to the fact that he required cues of greater precision to overcome his anomia. GM's higher level of underlying activation was sufficient for him to begin to form the approximate word-shape (e.g., knowing the number of syllables) but was not enough to complete the cohort reduction process. A small amount of additional information (the first phoneme or even the syllable number and stress pattern) was sufficient for 'lexical access' to be pushed over the inherent 'threshold' that is characteristic of the two-step dynamic. This graded approach also explains why Gainotti et al. [20] found that it was only the anomic patients without a comprehension deficit who had any ToT information, why the patients with the mildest anomia in the study by Pease and Goodglass [55] were the most likely to be successfully cued, and why those patients with little or no direct activation of phonology by semantics are apparently impossible to cue [24].

The distributed approach to speech production sketched out here does not mean that other models of lexical access cannot explain the data described in this article; indeed, we have attempted to provide possible solutions in the two sections above. The main difference between these accounts is the level of explanation adopted. It is, perhaps, a little ironic that we should be arguing for an account of speech production without intermediate localist representations in light of two patients who seem to be stuck between semantics and phonology, unable to retrieve the target word. It is quite possible, however, that these and other effects found in speech production are computational consequences of inherent factors that underlie the process(es) in question.

\section{Acknowledgements}

This work was completed while the first author was supported by grants from the EPSRC and NIH (to J. L. McClelland and K. Patterson). We would like to thank Andy Ellis, Sue Franklin, David Howard, 
Karalyn Patterson, and Mark Seidenberg for their useful comments and advice. We are particularly grateful to JS and GM for their support of this research.

\section{References}

[1] Allen J, Seidenberg MS. The emergence of grammaticality in connectionist networks. In: Macwhinney B, editor. The emergence of language. Mahweh, NJ: Lawrence Erlbaum Associated Inc, 1999.

[2] Baayen RH, Piepenbrock R, van Rijn H. The CELEX lexical database [CD-ROM]. Linguistics Data Consortium, Philadelphia, PA: University of Pennsylvania, 1993.

[3] Badecker W, Miozzo M, Zanuttini R. The two-stage model of lexical retrieval: Evidence from a case of anomia with selective preservation of grammatical gender. Cognition 1995;57:193-216.

[4] Best W, Howard D, Bruce C, Gatehouse C. Cueing the words: A single case study of treatments for anomia. Neuropsychological Rehabilitation 1997;7:105-41.

[5] Breen K, Warrington EK. Impaired naming and preserved reading: A complete dissociation. Cortex 1995;31:583-8.

[6] Brown AS. A review of the tip-of-the-tongue experience. Psychological Bulletin 1991;109:204-23.

[7] Butterworth B. Lexical access in speech production. In: Marslen-Wilson W, editor. Lexical representation and process. Cambridge, MA: The MIT Press, 1989.

[8] Butterworth B. Disorders of phonological encoding. Cognition 1992;42:261-86.

[9] Butterworth B, Howard D, McLoughlin P. The semantic deficit in aphasia: The relationship between semantic errors in auditory comprehension and picture naming. Neuropsychologia 1984;22:409-26.

[10] Caramazza A. How many levels of processing are there in lexical access? Cognitive Neuropsychology 1997;14:177-208.

[11] Caramazza A, Hillis AE. Where do semantic errors come from? Cortex 1990;26:95-122.

[12] Chater N, Christiansen MH. Connectionism and natural language processing. In: Garrod S, Pickering $\mathrm{M}$, editors. Language processing. London: UCL Press, 1999.

[13] Dell GS. A spreading activation theory of retrieval in sentence production. Psychological Review 1986;93:283-321.

[14] Dell GS, Juliano C, Govindjee A. Structure and content in language production: A theory of frame constraints in phonological speech errors. Cognitive Science 1993;17:149-95.

[15] Dell GS, O'Seaghdha PG. Stages of lexical access in speech production. Cognition 1992;42:287-314.

[16] Dell GS, Schwartz MF, Martin N, Saffran EM, Gagnon DA. Lexical access in aphasic and nonaphasic speakers. Psychological Review 1997;104:801-38.

[17] Farah MJ, McClelland JL. A computational model of semantic memory impairment: Modality specificity and emergent category specificity. Journal of Experimental Psychology, General 1991;120:339-57.

[18] Franklin S, Howard D, Patterson K. Abstract word anomia. Cognitive Neuropsychology 1995;12:549-66.

[19] Gainotti G, Miceli G, Caltagirone C, Silveri MC, Masullo C. The relationship between type of naming error and semanticlexical discrimination in aphasic patients. Cortex 1981;17:401-9.

[20] Gainotti G, Silveri MC, Villa G, Miceli G. Anomia with and without lexical comprehension disorders. Brain and Language 1986;29:18-33.

[21] Geschwind N. The varieties of naming error. Cortex 1967;3:96112.
[22] Goodglass H, Kaplan E, Weintraub S. Boston Naming Test. Philadelphia: Lea and Febiger, 1983.

[23] Goodglass H, Kaplan E, Weintraub S, Ackerman N. The 'tipof-the-tongue' phenomenon in aphasia. Cortex 1976;12:145-53.

[24] Graham KS, Patterson K, Hodges JR. Progressive pure anomia: Insufficient activation of phonology by meaning. Neurocase 1995;1:25-38.

[25] Henaff Gonon MA, Bruckert R, Michel F. Lexicalization in an anomic patient. Neuropsychologia 1989;27:391-407.

[26] Hillis AE, Rapp B, Romani C, Caramazza A. Selective impairment of semantics in lexical processing. Cognitive Neuropsychology 1990;7:191-243.

[27] Hodges JR, Graham N, Patterson K. Charting the progression of semantic dementia: Implications for the organisation of semantic memory. Memory 1995;3:463-95.

[28] Hodges JR, Patterson K, Oxbury S, Funnell E. Semantic dementia: Progressive fluent aphasia with temporal lobe atrophy. Brain 1992;115:1783-806.

[29] Howard D. Lexical anomia: Or the case of the missing lexical entries. Quarterly Journal of Experimental Psychology Human Experimental Psychology 1995;48a:999-1023.

[30] Howard D, Orchard Lisle V. On the origin of semantic errors in naming: Evidence from the case of a global aphasic. Cognitive Neuropsychology 1984;1:163-90.

[31] Howard D, Patterson K. The Pyramids and Palm Trees Test: A test of semantic access from words and pictures. Bury St Edmunds: Thames Valley Test Company, 1992.

[32] Jeschniak JD, Levelt WJM. Word frequency effects in speech production: Retrieval of syntactic information and of phonological form. Journal of Experimental Psychology: Learning, Memory and Cognition 1994;20:824-43.

[33] Kay J, Ellis A. A cognitive neuropsychological case-study of anomia: Implications for psychological models of word retrieval. Brain 1987;110:613-29.

[34] Kay J, Lesser R, Coltheart M. Psycholinguistic Assessments of Language Processing in Aphasia (PALPA). Hove: Lawrence Erlbaum Associates Ltd, 1992.

[35] Laine M, Kujala P, Niemi J, Uusipaikka E. On the nature of naming difficulties in aphasia. Cortex 1992;28:537-54.

[36] Laine M, Martin N. Lexical retrieval deficit in picture naming: Implications for word production models. Brain and Language 1996;53:283-314.

[37] Lambon Ralph MA. Distributed versus localist representations: Evidence from the study of item consistency in a case of classical anomia. Brain and Language 1998;64:339-60.

[38] Lambon Ralph MA, Cipolotti L, Patterson K, Oral naming and oral reading: Do they speak the same language?, Cognitive Neuropsychology 1999; (in press).

[39] Levelt WJM. Speaking: From intention to articulation. Cambridge, MA: MIT, 1989.

[40] Levelt WJM. Accessing words in speech production: Stages, processes and representations. Cognition 1992;42:1-22.

[41] Levelt WJM, et al. The time course of lexical access in speech production: A study of picture naming. Psychological Review 1991;98:122-42.

[42] Martin N, Gagnon DA, Schwartz MF, Dell GS, Saffran EM. Phonological facilitation of semantic errors in normal and aphasic speakers. Language and Cognitive Processes 1996;11:257-82.

[43] McClelland JL, Rumelhart DE. An interactive activation model of context effects in letter perception: Part 1. An account of basic findings. Psychological Review 1981;88:375-407.

[44] McKenna P, Warrington EK. The Graded Naming Test. Windsor, England: NFER-Nelson, 1983.

[45] Meyer AS. Investigation of phonological encoding through speech error analyses: Achievements, limitations, and alternatives. Cognition 1992;42:181-211.

[46] Meyer AS, Bock K. The tip-of-the-tongue phenomenon: 
Blocking or partial activation? Memory \& Cognition 1992;20:715-26.

[47] Miozzo M, Caramazza A. Retrieval of lexical-syntactic features in tip-of-the-tongue states. Journal of Experimental Psychology: Learning Memory and Cognition 1997;23:1410-23.

[48] Morton J, Naming. In: Newman S, Epstein R, editors. Current perspectives in dysphasia. Edinburgh: Churchill Livingstone, 1985.

[49] Morton J, Patterson KE. A new attempt at an interpretation, or, an attempt at a new interpretation. In: Coltheart $\mathrm{M}$, Patterson KE, Marshall JC, editors. Deep dyslexia. London: Routledge and Kegan Paul, 1980.

[50] Nickels L. The autocue? Self-generated phonemic cues in the treatment of a disorder of reading and naming. Cognitive Neuropsychology 1992;9:155-82.

[51] Nickels L, Howard D. A frequent occurrence? Factors affecting the production of semantic errors in aphasic naming. Cognitive Neuropsychology 1994;11:289-320.

[52] Nickels L, Howard D When the words won't come: Relating impairments and models of word production. In: Wheeldon L, editors. Language Production. UCL Press, London, 1999 (in press).

[53] Patterson K, Hodges JR. Deterioration of word meaning: Implications for reading. Neuropsychologia 1992;30:1025-40.

[54] Patterson K, Purell C, Morton J. Facilitation of word retrieval in aphasia. In: Code C, Muller D, editors. Aphasia Therapy. London: Edward Arnold, 1983.

[55] Pease D, Goodglass H. The effects of cueing on picture naming in aphasia. Cortex 1978;14:178-89.

[56] Plaut DC, Kello CT. The emergence of phonology from the interplay of speech comprehension and production: A distributed connectionist approach. In: MacWhinney B, editor. The emergence of language. Mahweh, NJ: Lawrence Erlbaum Associated Inc, 1999.

[57] Plaut DC, Shallice T. Deep dyslexia: A case study of connectionist neuropsychology. Cognitive Neuropsychology 1993;10:377-500.

[58] Podraza BL, Darley FL. Effect of auditory pre-stimulation on naming in aphasia. Journal of Speech and Hearing Research 1977;20:669-83.

[59] Raymer AM, et al. Cognitive neuropsychological analysis and neuroanatomic correlates in a case of acute anomia. Brain and Language 1997;58:137-56.

[60] Riddoch MJ, Humphreys GW. The Birmingham Object Recognition Battery (BORB). Hove: Lawrence Erlbaum Associated Ltd, 1992.

[61] Seidenberg MS. Language acquisition and use: Learning and applying probabilistic constraints. Science 1997;275:1599-603.

[62] Shallice T, Coughlan AK. Modality specific word comprehension deficits in deep dyslexia. Journal of Neurology, Neurosurgery and Psychiatry 1980;43:866-72.

[63] Shallice T, Warrington EK, McCarthy R. Reading without semantics. Quarterly Journal of Experimental Psychology 1983;35a:111-38.

[64] Snowden JS, Goulding PJ, Neary D. Semantic dementia: A form of circumscribed cerebral atrophy. Behavioural Neurology 1989;2:167-82.

[65] Strain E, Patterson K, Seidenberg MS. Semantic effects in single-word naming. Journal of Experimental Psychology: Learning, Memory, and Cognition 1995;21:1140-54.

[66] Valentine T, Moore V, Brédart S. Priming production of people's names. Quarterly Journal of Experimental Psychology 1995;48A:513-35.

[67] Warrington EK. The Graded Naming Test: A restandardisation. Neuropsychological Rehabilitation 1997;7:143-6. 